\title{
Simulación personalizada de la cirugía de inserción de anillos intraestromales (ICRS). Validación con datos clínicos
}

\author{
Julio Flecha* ${ }^{1}$, Miguel Ángel Ariza-Gracia ${ }^{1,2}$, Jesús Zurita ${ }^{3}$, Begoña Calvo ${ }^{1}$ \\ ${ }^{1}$ Grupo AMB Instituto de Investigación en Ingeniería de Aragón (I3A) \\ Universidad de Zaragoza, Mariano Esquillor s/n, 50018, Zaragoza, Spain \\ Tel. +34-976762707,*e-mail: jflecha@unizar.es \\ ${ }^{2}$ Institute for Surgical Technology and Biomechanics (ISTB), Universität Bern (Berna, Suiza) \\ ${ }^{3}$ Departamento de Ingeniería Mecánica, Energía y materiales, Universidad Pública de Navarra (Pamplona, España)
}

\section{Introducción}

Los anillos intraestromales (ICRS) se usan en la clínica oftalmológica para la estabilización de la progresión de la enfermedad ectásica no inflamatoria, que provoca la disurrupción de las fibras de colágeno, conocida como queratocono.

Este estudio tiene por obtetivo simular la cirugía de inserción de anillos intraestromales en pacientesespecíficos (PE), obteniendo la geometría del modelo de elementos finitos a partir de la topografía del paciente. A continuación se transformarán los resultados mecánicos en resultados ópticos, que permitan la comparación con las topografías corneales post-cirugia. Actualmente la planificación de la cirugía se basa en nomogramas estadísticos y en la experiencia del cirujano [1], por lo que la metodología propuesta puede ser una herramienta clínica que ayude a los médicos a una mejor planificación de la intervención o para evaluar el impacto posquirúrgico de diferentes escenarios y elegir la configuración óptima entre los siguientes parámetros: tamaño ICRS, posición corneal o profundidad de la cirugía.

\section{Materiales y Métodos}

Para la construccion de las malla de elementos finitos (EF) se parte de los datos de un paciente cuya topografía pre-cirugía se muestra en la Figura 1a. Este paciente fue diagnostado de queratocono paracentral con ejes topográfico y comático no coincidentes. El cirujano decidió implantar dos anillos de seccion triangular de 200 micras de espesor y $140^{\circ}$ de ángulo abarcado (Ferrara AR620140) localizados a $120^{\circ}$ y a $300^{\circ}$, tomando como origen el plano nasal-temporal (Figura 1a). Los anillos se insertan a una profundidad de 322 micras de espesor.

Se procede a reproducir dicho tratamiento de forma numérica. Para ello, se ha desarrollado un algoritmo que convierte la nube de puntos generada por los topógrafos comerciales (en este caso concreto Pentacam) en superficie anterior y posterior de la córnea [2]. La figura $1 \mathrm{~b}$ muestra la nube de puntos de la topografía corneal suministrada por el topógrafo. En ella se aprecia que la córnea no es simétrica debido a la ectasia o queratocono. El modelo de elementos finitos (Figura 1c) incluye cornea, limbo y esclera. Dichos tejidos utilizan modelos de material hiperelásticos, utilizando diferentes funciones densidad energía de deformación: para la córnea (2 familias ortogonales de fibras) y el limbo (1 familia cirunferencial de fibras) modelados anisótropos que consideran el modelo Neo-Hookeano (matriz extracelular) y el modelo propuesto por Holzapfel (fibras de colágeno). Para la esclera se utiliza el modelo isótropo de Yeoh. Las constantes de material se toman de Ariza-Gracia et al. [3]. Los segmentos ICRS se simulan como un plástico (PMMA, según fabricante) siguiendo modelo elástico de material $(\mathrm{E}=3300 \mathrm{MPa}$ y $v=0.4)$. Las condiciones de contorno aplicadas al modelo son la presión intraocular (IOP) registrada del paciente, previamente a la cirugía y simetría en el plano escleral.

La inserción de ICRS en el modelo de EF se realiza siguiendo la metodología descrita en Flecha-Lescún et al. [4]. La cual distingue los pasos siguientes: obtención de la configuración inicial del modelo, cirugía, inflado, inserción de ICRS y cierre.

Finalmente, los resultados mecánicos se transforman en resultados ópticos mediante un algoritmo de trazado de rayos [5]. Los resultados ópticos de la simulación se comparan con la topografía del paciente obtenida 1 mes después de la operación. Para validar la metodología, se compara el cambio de dioptrías pre- y post-cirugía.

\section{Resultados}

Al introducir los segmentos intraestromales, el ápex corneal se desplaza hacia la cámara interna del ojo y se alcanza un estado de relajación en la superficie anterior corneal (Figura 2a-arriba). Además, se induce un gradiente de tensiones a lo largo del espesor de la córnea que es el responsable de la estabilización del anillo en el interior de la córnea y no se produza una extrusión del anillo (Figura2aabajo).

Tras aplicar el algortimo de trazado de rayos a la geometría deformada de la córnea, se obtienen las características ópticas correspondientes a la postcirugia: mapas topografícos, potencia esférica y cilíndrica asi como las aberraciones corneales. La Figura $2 \mathrm{~b}$ muestra el mapa tangencial anterior, 
donde se puede observar como el queratocono se ha estabilizado notablemente gracias a la accion de los segmentos ICRS y hay una reduzcción de 6 dioptrías en el centro de la cornea: se pasa de $48 \mathrm{D}$ en la región donde se encuentra el queracono (Figura 1a) a 42 D (Figuras $2 b$ y 2c).

Finalmente, se valida la metodología comparando los resultados ópticos de la Figura $2 \mathrm{~b}$ con la óptica del paciente post-cirugía (fgura $2 \mathrm{c}$ ). Como se aprecia en las dos imágenes, se alcanzan valores de dioptrías muy similares, del orden de $40 \mathrm{D}$ en el centro corneal, y la forma del mapa tangencial anterior es la misma.

\section{Conclusiones}

Tras la validación del método con datos quirúrgicos de pacientes, la metodología puede ser utilizada como ayuda adicional por los cirujanos para visualizar la nueva topografía y comprobar qué potencia óptica es corregida.

Además, esta herramienta permitirá simular diferentes configuraciones de colocación de ICRS para una misma topografía y evuluar los resultados de cada una. Con esto, se podrá obtener la configuración que maximice la estabilización de la enfermedad y minimice las aberraciones inevitables, introducidas por inclusión del ICRS.

\section{AGRADECIMIENTOS}

JF ha sido financiado por el gobierno de España (DPI 201454981-R. Referencia: BES-2015-073630). Agradacer también a Qvision y al Dr. Joaquín Fernández por suministrarnos los datos de los pacientes.

\section{REFERENCIAS}

[1]. FERNÁNDEZ-VEGA L, LISA C, POO-LÓPEZ A, MADRID-COSTA D, MERAYO-LLOVES $J$ and ALFONSO JF (2016) Intraestromal corneal ring segment implantation in 409 paracentral keratoconic eyes. Cornea 35(11):1421-1426.

[2]. SIMMONINI I and PANDOLFI A (2015) Customized finite element modelling of the human cornea. PlosOne, 10(6): 1-23. https://doi.org/10.1371/journal.pone.0130426

[3]. ARIZA-GRACIA M.Á, REDONDO S, PIÑERO D, CALVO B and RODRÍGUEZ-MATAS J.F (2017) A predictive tool for determining patient-specific mechanical properties of human corneal tissue. Computer methods in applied mechanics and engineering 317 : 226-247. http://dx.doi.org/10.1016/j.cma.2016.12.013

[4]. FLECHA-LESCÚN J, CALVO B, ZURITA J, ARIZA-GRACIA M.Á (2018) Template-based methodology for the simulation of intracorneal segment ring implantation in human corneas. Biomechanics and Modelling in Mechanobiology 116. https://doi.org/10.1007/s10237-018-1013-z

[5]. ARIZA-GRACIA M.Á, ORTILLES A, CRISTÓBAL J, RODRÍGUES-MATAS J.F and CALVO B (2017) A numerical-experimental protocol to characterize corneal tissue with an application to predict astigmatic keratotomy surgery. Journal of Mechanical Behavior of Biomedical Materials 74: 304-314. http://dx.doi.org/10.1016/j.jmbbm.2017.06.017

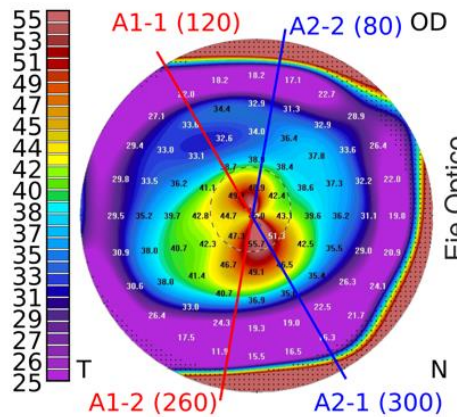

(a)

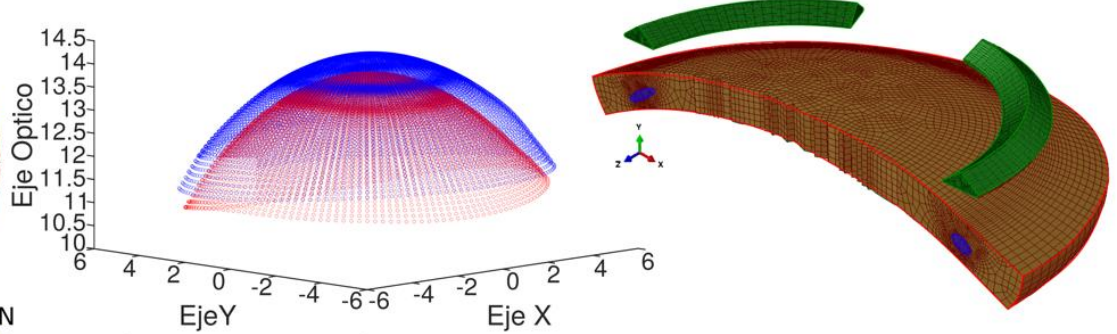

- Cornea Anterior o Cornea Posterior

(b) (c)

Fig 1. Material y métodos. (a) Mapa tangencial anterior del paciente pre-cirugia. (b) Nube de puntos de la cornea anterior y posterior de la topografía pre-cirugía. Datos del topógrafo. (c) Malla de EF obtenida a partir de la nube de puntos. Se muestra la seccion transversal del modelo 3D, en rojo la córnea; en azul los elementos que conforman la cirugía y en verde el modelo de anillo triangular insertado.

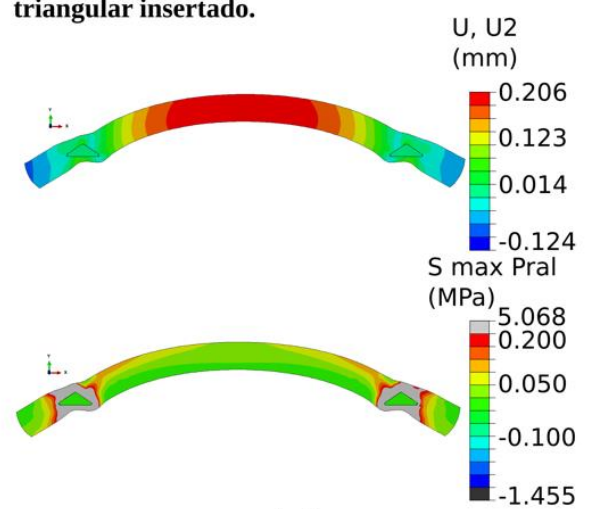

(a)

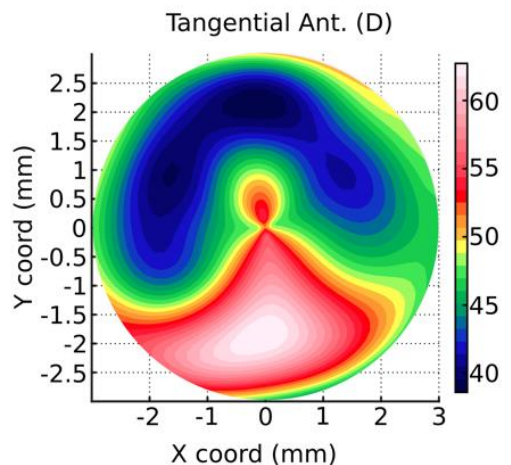

(b)

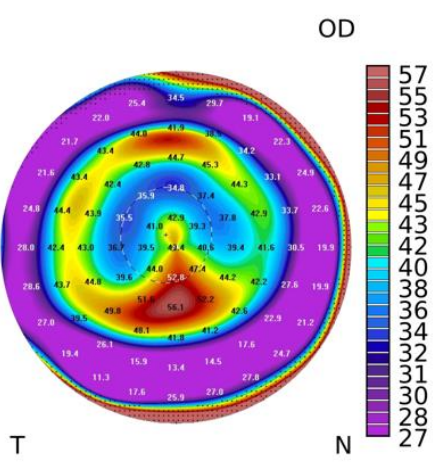

(c)

Fig 2.Resultados. (a) Resultados mecánicos. Imagen arriba: desplazamiento vertical de la seccion transversal. Imagen abajo: Tensión máxima principal de la sección transversal. (b) Resultados ópticos. Aplicando el algoritmo de trazado de rayos se obtienen los mapas topográficos. Se muestra el mapa tangencial anterior. (c) Mapa tangencial anterior del paciente post-cirugía. 